\title{
Determination of phytosterols in Oryza sativa L. cultivars by liquid chromatography atmospheric chemical ionization time-of-flight mass spectrometer (LC-APCI-TOF-MS) coupled with a modified QuEChERS method
}

\author{
Seung Rok Lee ${ }^{*}$, Dong Cheon Yun ${ }^{*}$, Seung Ho Lee, Si Young Yang, In Seon Kim ${ }^{\#}$
}

Division of Applied Bioscience and Biotechnology, Institute of Environmentally-Friendly Agriculture, College of Agriculture and Life Sciences, Chonnam National University, Gwangju, South Korea; ${ }^{\#}$ Corresponding Author: mindzero@,chonnam.ac.kr.

Received 3 September 2012; revised 15 October 2012; accepted 28 October 2012

\begin{abstract}
Development of analytical methods for the determination of phytosterols in whole grains is one of growing interests due to their clinical and nutritional functions in human. In this study, we examined simultaneous determination of $\beta$-sitosterol, stigmasterol and campesterol in Korean rice cultivars by liquid chromatography atmospheric chemical ionization time-of-flight mass spectrometer (LC-APCI-TOF-MS). The hulled rice samples were extracted using a modified QuEChERS and analyzed by LC-APCI-TOF-MS. The method was validated by low limit of detection (LOD) and limit of quantification (LOQ) values and high recovery values with low relative standard deviation (RSD). The highest concentration of sitosterol was detected in Hwasung and Undu rice cultivars, exhibiting approximately 195.5 and $191.7 \mathrm{mg} / \mathrm{Kg}$, respectively. Stigmasterol and campesterol were detected at the highest level in Hwasung rice cultivar, giving the concentrations of approximately 70.0 and $53.9 \mathrm{mg} / \mathrm{Kg}$, respectively. Sitosterol was determined to be a main phytosterol detected in the rice samples. Our data demonstrated that LCIAPCI-TOF-MS coupled with QuEChERS method can be used as a simple tool for the determination of phytosterols in rice samples.
\end{abstract}

Keywords: Campesterol; Phytosterols; QuEChERS; Sitosterol; Stigmasterol; Rice

\footnotetext{
*Lee SR and Yun DC contributed equally.

"Corresponding author.
}

\section{INTRODUCTION}

Phytosterols have shown to function as biologically active substrates that contribute to reduce the risk of human diseases [1,2]. Biological functions of phytosterols have been demonstrated by their cholesterol-reducing properties and anticancer effects [3,4]. Typical representatives of phytosterols found commonly in plants [5] include sitosterol, stigmasterol and campesterol (Figure 1). They have attracted much attention due to their nutritional properties as natural components of regular diet [6-8]. Physterols have also attracted much attention in whole grains because the increased consumption of whole grain products is associated with the reduced risk of chronic disease [9]. Whole grains contain a variety of phytochemicals such as sterol and phenolic compounds that associate with the health benefits $[10,11]$. In particular, rice (Oryza sativa L.) is known to contain unique phytosterols that complement in the fruits and vegetables when consumed together [12]. Rice is one of the major cereals consumed largely as a regular diet in Asian countries. In Korea, particularly, rice has been consumed in a variety of diet products from cookies to regular foods. Phytosterols might play an important role in the functional benefits attributed to the consumption of rice.

The beneficial effects of phytosterols in human health have triggered much study on the development of analytical methods for quantitative determination of phytosterols in diet sources. General methods used for the determination of phytosterols include gas liquid chromatography [13] and high performance liquid chromatography [14]. Mass spectrometry methods connected with gas and liquid chromatography have accepted as power tools for the detection of phytosterols in complicated samples $[15,16]$. These methods, however, are time-con 


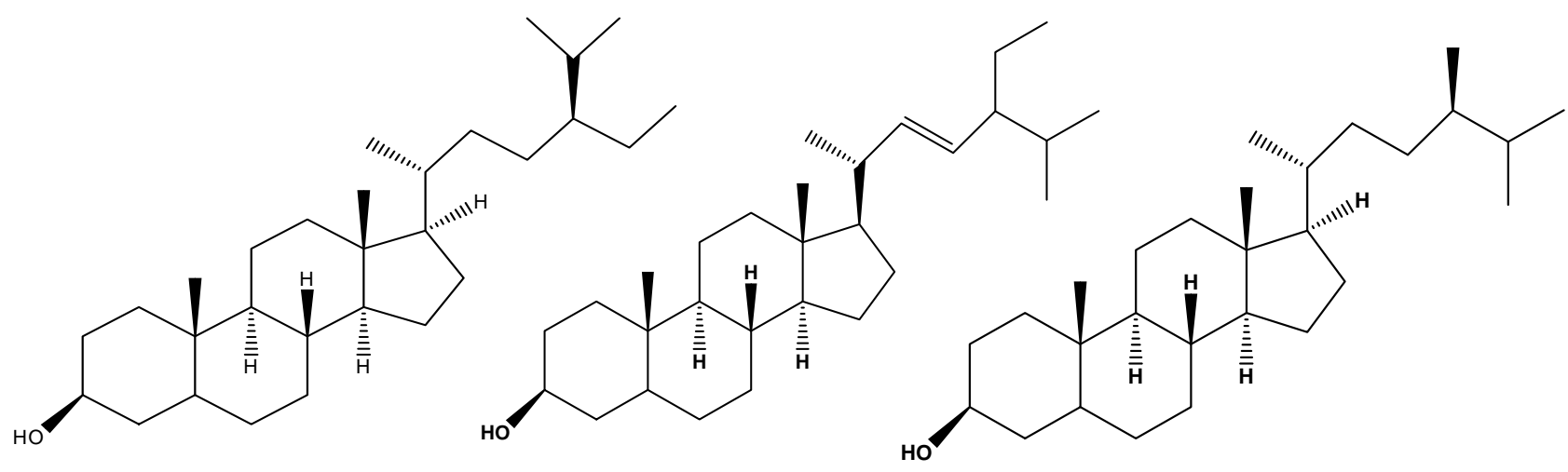

(1)

(2)

(3)

Figure 1. Chemical structures of sitosterol (1), stigmasterol (2) and campesterol (3).

suming and generating organic solvents wastes during the sample preparation such as liquid-liquid extraction and derivatization procedures. A potential risk of interference between analytes and co-eluted components is additional limit to these methods. Thus, more simple and environmental-friendly methods are required for the sample preparation. To date, the quick, easy, effective, rugged and safe (QuEChERS) method has been introduced as a simple tool for simultaneous analysis of multiple targets [17]. QuEChERS involves microscale extraction using a small amount of organic solvent followed by purifying the extract using dispersive solid phase extraction (SPE). QuEChERS avoids producing solvent wastes and consuming time and labor that are required in the general methods [18]. The present study reports the development of a simple method for simultaneous determination of phytosterols, such as sitosterol, campesterol and stigmasterol, in rice samples using liquid chromatography atmospheric chemical ionization timeof-flight mass spectrometer (LC-APCI-TOF-MS) coupled with a modified QuEChERS sample preparation.

\section{MATERIALS AND METHODS}

\subsection{Chemicals and Reagents}

Stigmasterol (95\%), $\beta$-sitosterol (95\%), campesterol (65\%), $5 \alpha$-cholestan- $3 \beta$-ol (95\%), and cholesterol (94\%) were purchased from Sigma-Aldrich (MO, USA). Solvents used in the study were of HPLC grade purchased from Fisher Scientific (PA, USA). All chemicals used were of analytical grade commercially available, unless otherwise stated.

\subsection{Rice Cultivars}

Rice cultivar samples were kindly provided by the National Seed and Variety Service, Republic of Korea. The rice was cultivated in Chonnam province, Republic of Korea, under the same conditions.

\subsection{Instrumentation and Analytical Conditions}

Liquid chromatography-atmospheric pressure chemical ionization-time-of-flight mass spectrometry (LC-APCITOF-MS) was a Bruker Daltonics micro-TOF mass spectrometer connected with a Dionex model P680 HPLC equipped with a Dionex model PDA-100 photodiode array detector (PDA). The HPLC column was a SunFire C-18 stainless steel column $(2.1 \mathrm{~mm} \times 50 \mathrm{~mm}, 5 \mu \mathrm{m}$ thickness $)$. The mobile phase consisted of a solvent mixture of methanol and water $(97: 3, \mathrm{v} / \mathrm{v})$ and flowed at a rate of $0.7 \mathrm{~mL} / \mathrm{min}$. APCI-TOF-MS conditions were as follows: capillary voltage, $4000 \mathrm{~V}$; nebulizer pressure, 0.4 bar; drying gas, $4 \mathrm{~L} / \mathrm{min}$; gas temperature, $250^{\circ} \mathrm{C}$; hexapole $\mathrm{RF}, 300 \mathrm{~V}$; collision $\mathrm{RF}, 250 \mathrm{~V}$; collision energy, $6 \mathrm{eV}$. The accurate mass spectra were recorded from 50 to $800 \mathrm{~m} / \mathrm{z}$. MS analyzer was calibrated with a sodium formate solution consisting of a mixture of $10 \mathrm{mM}$ sodium hydroxide in isopropanol and $0.2 \%(\mathrm{v} / \mathrm{v})$ formic acid at a ratio of $1: 1(\mathrm{v} / \mathrm{v})$, as described previously [19]. The calibration mixture was injected at the beginning and end of each run via a sixportdivert valve equipped with a $100 \mu \mathrm{L}$ sample loop. The exact masses of the calibration ions were calculated by using the Bruker Data Analysis version 3.4 software as follows: $(\mathrm{M}+\mathrm{H})^{+} \mathrm{Na}(\mathrm{NaCOOH})_{2} \mathrm{~m} / \mathrm{z}$ 158.9641, Na$(\mathrm{NaCOOH})_{3} \mathrm{~m} / \mathrm{z} 226.9515, \mathrm{Na}(\mathrm{NaCOOH})_{4} \mathrm{~m} / \mathrm{z} 294.9389$, $\mathrm{Na}(\mathrm{NaCOOH})_{5} \quad \mathrm{~m} / \mathrm{z} \quad 362.9263, \quad \mathrm{Na}(\mathrm{NaCOOH})_{6} \quad \mathrm{~m} / \mathrm{z}$ $430.9138, \mathrm{Na}(\mathrm{NaCOOH})_{7} \mathrm{~m} / \mathrm{z} 498.9012, \mathrm{Na}(\mathrm{NaCOOH})_{8}$ $\mathrm{m} / \mathrm{z}$ 566.8886, Na(NaCOOH$)_{9} \mathrm{~m} / \mathrm{z}$ 634.8760, Na(Na$\mathrm{COOH})_{10} \mathrm{~m} / \mathrm{z} 702.8635, \mathrm{Na}(\mathrm{NaCOOH})_{11} \mathrm{~m} / \mathrm{z} 770.8509$.

\subsection{Sample Preparation}

The hulled rice samples were prepared with a QuEChERS method modified from the previous study [20]. Briefly, 5 g-portion of the rice samples were homogenized and weighed into $50 \mathrm{ml}$-size falcon tubes. The tubes were added $15 \mathrm{ml}$ of acetonitrile and $10 \mathrm{ml}$ of distilled water and vigorously mixed for 1 min using a vor- 
tex mixer. The tubes were then added $6 \mathrm{~g}$ of $\mathrm{MgSO}_{4}$ and $1.5 \mathrm{~g}$ of sodium acetate and immediately mixed for $1 \mathrm{~min}$. The tubes were centrifuged at $3000 \mathrm{rpm}$ for $5 \mathrm{~min}$ using a tabletop centrifuge. The organic phase was transferred carefully into a $50 \mathrm{ml}$-size falcon tubes containing 300 $\mathrm{mg}$ of PSA and $900 \mathrm{mg}$ of $\mathrm{MgSO}_{4}$ and mixed vigorously for $1 \mathrm{~min}$. The tubes were centrifuged again as described above. An aliquot of the extracts was subjected to LC/ APCI-TOF-MS analysis.

\subsection{Method Validation}

The calibration curves of pytosterols were prepared with working solutions in a range of 0.001 to $100 \mathrm{mg} / \mathrm{L}$ which had been diluted from the stock solutions (10 $\mathrm{mg} / \mathrm{L})$. An aliquot of the working solutions in triplicate was injected onto LC/APCI-TOF-MS, and their linearity was investigated on the basis of peak area. The matrix effects of the sample extracts on the response of TOF-MS were examined by calculating the linearity of the phytosterol standards added in the control samples at the range above. Limit of detection (LOD) and limit of quantitation (LOQ) were determined at a signal-to-noise $(\mathrm{S} / \mathrm{N})$ ratio of $3: 1$ and $10: 1$, respectively, by injecting a series of the working solutions in triplicate. The accuracy of mass detection was determined by injecting three preparations of phytosterols added to the control samples at a level of $0.1 \mathrm{mg} / \mathrm{L}$, calculating the relative standard deviation. Recovery tests were carried out by determining an internal standard $5 \alpha$-cholestan $3 \beta$-ol fortified in the control samples at the levels of $0.5,1.0$, and $2.0 \mathrm{mg} / \mathrm{L}$. Allexperiments were performed in triplicate, unless other-wise stated.

\section{RESULTS AND DISCUSSION}

The methods of LC-APCI-TOF-MS for the determination of phytosterols were validated by examining the linearity of their calibration curves. The data are presented in Table 1. The calibration equation for sitosterol was $\mathrm{Y}=15.567 \mathrm{x}+4785$. The equations were $\mathrm{Y}=11.645 \mathrm{x}$
+1549 and $\mathrm{Y}=4.525 \mathrm{x}+397.4$ for campesterol and stigmasterol, respectively. A high linearity was achieved over a wide concentration from 0.1 to $100 \mathrm{mg} / \mathrm{L}$, with correlation coefficient values $\left(\mathrm{R}^{2} \geq 0.997\right)$. The limits of detection (LOD) were 100, 100 and $200 \mathrm{ng} / \mathrm{mL}$ for sitosterol, campesterol and stigmasteol, respectively. The limits of quantification (LOQ) were 200, 200 and $400 \mathrm{ng} / \mathrm{mL}$ for sitosterol, campesterol, and stigmasteol, respectively. LC-APCI-TOF-MS analyses detected $\left[\mathrm{M}+\mathrm{H}-\mathrm{H}_{2} \mathrm{O}\right]^{+}$peaks of phydrosterols, generating m/z 397.38 for sitosterol, $\mathrm{m} / \mathrm{z}$ 395.38 for stigmasterol and $\mathrm{m} / \mathrm{z} 383.37$ for campesterol, respectively (Table 2). Although the retention times of phytosterols on the HPLC column were not significantly different between them, the extract ion chromatogram (XIC) could selectively detect each phytosterol. This suggested that phytosterols could be determined simultaneously by LC-APCI-TOF-MS. Rice whole grains have been reported to contain a number of phytosterols [11, 12]. Thus, cholestan $3 \beta$-ol was used as an internal standard for recovery test, as its chemical structure is similar to the phytosterols. Recovery values of $5 \alpha$-cholestan $3 \beta$-ol ranged from approximately $97.6 \%$ to $100 \%$ at the levels of $0.5,1.0$ and $2.0 \mathrm{mg} / \mathrm{L}$, with relative standard deviation 0.61 to 5.60 (Table 3). These suggested that the method used in this study was successfully applicable to extract and determined pytosterols in the rice samples.

The validated method above was applied to determine pytosterols in the rice cultivar samples. The rice cultivar samples were extracted using the modified QuEChERS method and subjected to LC-APCI-TOF-MS analyses. Table 4 presents the data for the concentration of sitosterol was detected in Hwa-Sung rice cultivar at a level of approximately $195.4 \mathrm{mg} / \mathrm{kg}$ and in $U n-D u$ rice cultivar at a level of approximately $191.7 \mathrm{mg} / \mathrm{kg}$. The concentrations of stigmasterol and campesterol were highly detected in Hwa-Sung rice cultivar at levels of approximately 70.0 $\mathrm{mg} / \mathrm{kg}$ and $53.9 \mathrm{mg} / \mathrm{kg}$, respectively. Sitosterol was determined to be a main phytosterol detected in the rice samples, while campestrol was determined to be a minor.

Table 1. Calibration parameters for the detection of pytosterols by LC-APCI-TOF-MS.

\begin{tabular}{cccc}
\hline Sterol & Concentration $(\mathrm{mg} / \mathrm{kg})$ & Linearity $(n=3)$ & $\mathrm{R}^{2}$ value \\
\hline Sitosterol & $0.1-100.0$ & $\mathrm{Y}=15.567 x+4785$ & 0.997 \\
Campesterol & $0.1-100.0$ & $\mathrm{Y}=11.645 x+1549$ & 0.998 \\
Stigmasterol & $0.2-100.0$ & $\mathrm{Y}=4.525 x+397.4$ & 0.998 \\
\hline
\end{tabular}

Table 2. Target ions of phytosterols and their corresponding retention times.

\begin{tabular}{ccc}
\hline Sterol & Retention time $(\min )$ & $\mathrm{m} / \mathrm{z}\left(\mathrm{M}+\mathrm{H}-\mathrm{H}_{2} \mathrm{O}\right)^{+}$ \\
\hline Sitosterol & 4.5 & 397.38 \\
Stigmasterol & 3.9 & 395.37 \\
Campesterol & 4.0 & 383.37 \\
\hline
\end{tabular}


Table 3. Recovery of the internal standard $5 \alpha$-chloestan- $3 \beta$-ol fortified in the rice samples.

\begin{tabular}{cccc}
\hline \multirow{2}{*}{ Compound } & \multicolumn{3}{c}{ Recovery $(\%)^{\mathrm{a}}$} \\
\cline { 2 - 4 } & \multicolumn{3}{c}{ Spiked concentration $(\mathrm{mg} / \mathrm{kg})$} \\
\cline { 2 - 4 } & 0.5 & 1.0 & 2.0 \\
\hline $5 \alpha$-chloestan-3 $\beta$-ol & $100 \pm 5.60$ & $97.6 \pm 0.61$ & $98.3 \pm 1.63$ \\
\hline${ }^{\mathrm{a}}$ Data are means \pm RSD of triplicate. & & & \\
& &
\end{tabular}

Table 4. Concentrations of the phytosterols determined in the rice samples by LC-APCI-TOF-MS ${ }^{\mathrm{a}}$.

\begin{tabular}{ccccccc}
\hline \multirow{2}{*}{ Rice cultivar } & \multicolumn{2}{c}{ Sitosterol } & \multicolumn{2}{c}{ Stigmasterol } & \multicolumn{3}{c}{ Campesterol } \\
\cline { 2 - 7 } & $\mathrm{mg} / \mathrm{kg}$ & $\mathrm{RSD}(\%)$ & $\mathrm{mg} / \mathrm{kg}$ & $\mathrm{RSD}(\%)$ & $\mathrm{mg} / \mathrm{kg}$ & $\mathrm{RSD}(\%)$ \\
\hline Koshiikari & 155.01 & 9.61 & 50.14 & 3.71 & 22.47 & 2.55 \\
Daejin & 116.64 & 4.31 & 48.98 & 2.34 & 22.71 & 5.8 \\
Dongjin & 94.60 & 3.49 & 38.04 & 4.23 & 29.15 & 8.34 \\
Saekyewa & 87.03 & 3.87 & 33.67 & 9.80 & 28.18 & 2.76 \\
Un-du & 191.73 & 1.47 & 30.55 & 5.98 & 27.48 & 3.91 \\
Hwasumg & 195.45 & 6.37 & 70.02 & 5.66 & 53.92 & 6.94 \\
Hitomebori & 136.29 & 8.17 & 54.72 & 0.39 & 35.24 & 2.10 \\
\hline
\end{tabular}

${ }^{\mathrm{a}}$ Data are means of triplicate.

Significant variations in the concentrations of phytosterols between the rice cultivars suggested that phytosterols could be found depending on rice cultivars. The relative standard deviation (RSD) was less than about 9.6\%, suggesting that the experimental error of the employed method was insignificant.

Phytosterols such as sitosterol, campesterol and stigmasterol have received much attention due to their clinical and nutritional functions. One of the reasons that phytosterols are attractive to human is that they can be consumed as a complement in the foods. Thus, searching food containing phytosterols has required analytical methods to detect quantitatively them. The present study demonstrated that LC/APCI-TOF-MS coupled with QuEChERS method can be used as a simple tool for the determination of phytosterols in rice samples.

\section{REFERENCES}

[1] Tham, D.M. (1998) Potential health benefits of dietary phytoestrogens: A review of the clinical, epidemiological, and mechanistic evidence. The Journal of Clinical Endocrinology and Metabolism, 83, 2223-2235. doi:10.1210/jc.83.7.2223

[2] Piironen, V., Lindsay, D., Miettinen, T., Toivo, J. and Lampi A.-M. (2000) Plant sterols: Biosynthesis, biological function and their importance to human nutrition. Journal of the Science of Food and Agriculture, 80, 939-966. doi:10.1002/(SICI)1097-0010(20000515)80:7<939::AIDJSFA644>3.0.CO;2-C

[3] Awd, A.B. and Fink, C.S. (2000) Phytosterols as anticancer dietary components: Evidence and mechanism of action. Journal of Nutrition, 130, 2127-2130.

[4] Andersson, S.W., Skinner, J., Ellegard, L., Welch, A.A., Bingham, S., Mulligan, A., Andersson, H. and Khaw, K.T.
(2004) Intake of dietary plant sterols in inversely related to serum cholesterol concentration in men and women in the EPIC Norfolk populations: A cross-sectional study. European Journal of Clinical Nutrition, 58, 1378-1385. doi:10.1038/sj.ejen. 1601980

[5] Akihisa, T., Kokke, W. and Tamura, T. (1991) Naturally occurring sterols and related compounds from plants. In: Patterson, G.W. and Nes, W.D., Eds., Physiology and Biochemistry of Sterols, American Oil Chemists' Society, Champaign, 172-228.

[6] Eussen, S.R.B.M., Feenstra, T.L., Toxopeus, I.B., Hoekstra, J., Klungel, O.H., Verhagen, H., Van Karen, H.J. and Rompelberg, C.J.M. (2011) Costs and health effects of adding functional foods containing physterols/-stanols to statin therapy in the prevention of cardiovascular disease. European Journal of Pharmacology, 668, S91-S100. doi:10.1016/j.ejphar.2011.05.081

[7] Choudhary, S.P. and Tran, L.S. (2011) Phytosterols: Perspectives in human nutrition and clinical therapy. Current Medicinal Chemistry, 18, 4557-4567. doi:10.2174/092986711797287593

[8] Jones, P.J. and Abumweis, S.S. (2009) Phytosterols as functional food ingredients: Linkages to cardiovascular disease and cancer. Current Opinion in Clinical Nutrition and Metabolic Care, 12, 147-151. doi:10.1097/MCO.0b013e328326770f

[9] Liu, R.H. (2007) Whole grain phytochemicals and health. Journal of Cereal Science, 46, 207-219. doi:10.1016/j.jcs.2007.06.010

[10] Lu, T.-J., Chen, H.-N. and Wang, H.-J. (2011) Chemical constituents, dietary fiber, and $\gamma$-oryzanol in six commercial varieties of brown rice from Taiwan. Cereal Chemistry, 88, 463-466. doi:10.1094/CCHEM-09-10-0132

[11] Gani, A., Wani, S.M., Masoodi, F.A. and Hameed, G. (2012) Whole-grain cereal bioactive compounds and their health benefits: A review. Food Processing and Technology, 3, $1-10$. 
[12] Lloyd, B.J., Siebenmorgen, T.J. and Beers, K.W. (2000) Effect of commercial processing on antioxidants in rice ban. Cereal Chemistry, 77, 551-555. doi:10.1094/CCHEM.2000.77.5.551

[13] Phillips, K.M., Ruggio, D.M. and Bailey, J.A. (1999) Precise quantitative determination of phytosterols, stanols, and cholesterol metabolites in human serum by capillary gas-liquid chromatography. Journal of Chromatography $B$, 732, 17-29. doi:10.1016/S0378-4347(99)00257-1

[14] Kasama, T., Byun, D.-S. and Seyama, Y. (1987) Quantitative analysis of sterols in serum by high performance liquid chromatography: Application to the biochemical diagnosis of cerebrotendinous xanthomatosis. Journal of Chromatography A, 400, 214-246.

[15] Chevy, F., Humbert, L. and Woilf, C. (2005) Sterol profiling of amniotic fluid: A routine method for the detection of distal cholesterol synthesis deficit. Prenatal Diagnosis, 25, 1000-1006. doi:10.1002/pd.1254

[16] Careri, M., Elviri, L. and Mangia, A. (2001) Liquid chromatography-UV determination and liquid chromatography-atmospheric pressure chemical ionization mass spectrometric characterization of sitosterol and stigmasterol in soybean oil. Journal of Chromatography A, 935, 249-257. doi:10.1016/S0021-9673(01)01079-2

[17] Anastassiades, M., Lehotay, S.J., Stajnbaher, D. and Schenck, F.F. (2003) Fast and easy multiresidue method employing acetonitrile extraction/partitioning and "dispersive solidphase extraction" for the determination of pesticide residues in produce. Journal of AOAC International, 86, 412-431.

[18] Gilbert-López, B., García-Reyer, J.F., Mezcua, M., Milina-Díaz, A. (2009) Sample treatment and determination of pesticide residues in fatty vegetable matrices. Talanta, 79, 109-128. doi:10.1016/j.talanta.2009.04.022

[19] Bong, M.S., Yang, S.Y., Lee, S.H., Seo, J.M. and Kim, I.S. (2011) Simultaneous analysis of conazole fungicides in garlic by Q-TOF mass spectrometer coupled with a modified QuEChERS method. Korean Journal of Environmental Agriculture, 30, 324-330.

[20] Lehotay, S., Son, K., Kwon, H., Koesukwiwat, U., Fu, W., Mastovska, K., Hoh, E. and Leepipatpiboon, N. (2010) Comparison of QuEChERS sample preparation methods for the analysis of pesticide residues in fruit and vegetables. Journal of Chromatography A, 1217, 2548-2560. doi:10.1016/j.chroma.2010.01.044 